https://helda.helsinki.fi

\title{
The nativization of pragmatic borrowings in remote language contact situations
}

\section{Peterson, Elizabeth}

2017-05

Peterson , E 2017 , ' The nativization of pragmatic borrowings in remote language contact situations ' , Journal of Pragmatics , vol. 113 , pp. 116-126 . https://doi.org/10.1016/j.pragma.2017.02.012

http://hdl.handle.net/10138/233792

https://doi.org/10.1016/j.pragma.2017.02.012

unspecified

acceptedVersion

Downloaded from Helda, University of Helsinki institutional repository.

This is an electronic reprint of the original article.

This reprint may differ from the original in pagination and typographic detail.

Please cite the original version. 
The nativization of pragmatic borrowings due to foreign language contact

Elizabeth Peterson, University of Helsinki

This article focuses on the issue of pragmatic borrowing and how it manifests in language contact settings where the language of influence is a nonnative language for the receiving speech community. In this case, the languages under investigation are English and its unidirectional influence on Finnish. The article first establishes the behavior of pragmatic elements in traditional language contact settings, then moves on to problematize the notion within contemporary language contact settings. The article then moves on to specific examples of pragmatic borrowings from English into Finnish, including pliis ('please'), oh my god, and about. The discussion accounts for the social, pragmatic, semantic and grammatical incorporation of these elements into Finnish, demonstrating that the borrowed forms have characteristics which are distinct from both the source language (English) as well as heritage form in the recipient language (Finnish). Included in the discussion of these forms is a proposed trajectory for how such borrowings enter into native discourse, as well as the success vs. failure of pragmatic borrowings in entering mainstream discourse.

language contact, discourse markers, indexical field, pragmatic borrowing, English, Finnish

1. Introduction

The term pragmatic borrowing refers to the incorporation of pragmatic and discursive elements into a recipient language (Andersen, 2014). Although the phenomenon to which the term refers had been previously observed (as detailed in Andersen, 2014; see also Terkourafi, 2011), Andersen's article was the first to chronicle the work by himself and other researchers and to legitimize their efforts through the coining of a name for this type of 
investigation. With pragmatic borrowing, researchers are interested not in merely listing borrowings, but in observing and accounting for their social, pragmatic and linguistic functions within recipient languages.

While research on pragmatic borrowing is by no means limited to languages in contact with English, the work detailed by Andersen (2014) investigates pragmatic borrowings from English into other (mostly European) languages, which seems logical, given the role of English as a widespread foreign language and lingua franca throughout much of Europe. Presumably, however, any language serving as a language of prestige in some contexts could qualify as a source of pragmatic borrowings¹.

The goals of this article are twofold. The primary goal is to follow up on Andersen's (2014) introduction to pragmatic borrowing by offering information about the functional, social, and pragmatic properties of pragmatic borrowings within a recipient language. A secondary goal is to address the under-explored issue of language contact involving a language which has foreign language status within a given territory, as is the case of English in Finland. "Foreign language status" is taken here to mean locations where English is, in general, formally acquired and/or serves lingua franca purposes, often in specific domains. In Finland, research on pragmatic borrowing is at the initial stages. For

${ }^{1}$ Quist (2008), for example, discusses the use of Arabic-sourced wallah'l swear by (the name of) God' as a multifunctional discourse marker (among other grammatical uses) in the speech of Copenhagen youth. 
this reason, the work presented in this article is based on the author's own analyses, as well as collaboration with students and colleagues.

The article first offers a brief overview of proposed linguistic universals of language contact and borrowing, narrowing in on pragmatic features. It then moves on to discuss how pragmatic elements behave in contact situations which involve a foreign language, establishing the choice of terminology in this article. Section 3 presents the contextualization of borrowings from English into Finnish. Section 4 presents a proposed trajectory for the adaptation of pragmatic borrowings, as well as providing counter examples and involved risk. Section 5 concludes the article with a few considerations about future directions for work on pragmatic borrowing, as well as work on foreign language contact settings.

$2 \quad$ Pragmatic borrowing

This section offers a general overview of contact phenomena relating to linguistic borrowing, highlighting in particular pragmatic borrowings in foreign language contact settings.

\subsection{Borrowing in language contact situations}

In the literature on language contact, there is a wide consensus that the directionality and specific outcomes of borrowing depend on a number of large- and small-scale linguistic and social factors (Matras, 2009; Meyers- 
Scotton, 2002; Sankoff, 2001; Thomason, 2001; Winford, 2001). Even so, there are several accounts that make note of supposed universals in contact settings and a cline of borrowability. For example, in the seminal work of Thomason and Kaufman (1988), it is noted that the typical pattern in borrowing situations is to first borrow words, with structural features coming later - if at all.

Much of the work on borrowing in contact situations hesitates to offer generalizations about outcomes, citing in part the unpredictable nature of language external factors (e.g., Sankoff, 2001; Thomason, 2001; Winford, 2001). Matras (2009) advances a strong argument that, in fact, linguistic universals and markedness account for much of what can be borrowed, and in what order linguistic elements are borrowed - at least in traditional (or "strong"; see Section 2.3) contact settings. Matras (2009:161-2) proposes several hierarchies for borrowability, including what he calls the "utilitarian hierarchy," having to do with the frequency and usefulness of forms within particular contexts.

Exceptions from the proposed hierarchies (which also include "accessibility" hierarchies and "speaker's intention with or overt reference to presupposition domain," Matras 2009: 161) imply extraneous constraints on the system, which, with the case of lexical borrowing, for example, includes a need or desire to fill gaps or convey prestige (Matras, 2009:151; see also Section 2.3). When it comes to structural borrowing, for example sentence 
structure/word order or discourse markers, exceptions to the hierarchies are related to cognitive processing at the level of the bilingual individual; such forms are difficult for bilingual speakers to disambiguate between their respective languages. Features such as discourse markers are singled out for discussion in this article, then, because of their special properties and behavior.

With the case of pragmatic borrowing co-opting English-sourced discourse markers into a native language does not depend on individual bilingualism. Discourse markers, as an example of pragmatic borrowing, can be and are used by individuals to express social meaning, even for semiproficient speakers (discussed in Section 2.2). In this sense, pragmatic borrowing of English-sourced features is reminiscent of the discussion of multi-ethnolects (for example, Nortier and Dorleijn, 2013) and metrolingualism (Pennycook and Otsuji, 2015), where the structural boundaries of languages and notions such as monolingualism and bilingualism are rendered problematic; speakers freely utilize the linguistic tools that are available to them, regardless of whether or not it constitutes a "language."

\subsection{Borrowing of pragmatic elements in contact situations}

In his introductory overview of the term pragmatic borrowing, Andersen (2014:17) notes that, while his focus is on the role of borrowings from English, in general the term refers to the borrowing of interjections, discourse markers, 
expletives, vocatives, general extenders, tags, focus constructions, intonation and paralinguistic phenomena. The common characteristic of these linguistic features is that they do not add to the propositional content of an utterance, but rather "carry signals about speaker attitudes, the speech act performed, discourse structure, information state, politeness, etc." (Andersen, 2014:17-18).

It has long been established that in apparently any type of language contact setting, features like those mentioned by Andersen are at the top position of the borrowability hierarchy (see, e.g, Muysken, 2013). From a cognitive point of view, the generally accepted explanation (Matras, 2009; Mougeon and Beniak, 1991) is that, as discussed in the previous subsection, bilingual speakers fail to separate such features in their linguistic repertoire. In other words, when speaking Language A, a bilingual speaker may freely incorporate pragmatic elements from Language $\mathrm{B}$.

As a representative example of the type of features included under the rubric of "pragmatic borrowings," discourse markers are singled out here for examination. A general account of discourse markers notes the following linguistic features (adapted from Müller 2005:4-8):

- Difficulty in assigning to any one word class

- Syntactic independence and grammatical optionality

- Lack of propositional content

- Orality

- Multifunctionality 
- High level of salience

The term discourse markers itself accounts for a range of features present at the discursive, grammatical or lexical level (Schiffrin, 1987), and which have been investigated from various perspectives, including discursive, pragmatic, and interactional sociolinguistics (Maschler and Schiffrin, 2015). Matras (2009:193) mentions the pragmatic detachability of discourse markers from a structural standpoint, also designating them as para-word forms, or "gesturelike devices."

The characteristics and functions of discourse markers leads to interesting and often contradictory uses in contact situations. For example, discourse markers are highly practical for even semi-proficient users of a language, due to their non-declension and non-integration within a clause; at the same time, the salience of discourse markers lends readily recognizable social and pragmatic associations. Thus, they simultaneously convey both mastery and non- mastery of a language. These contrasting observations are mentioned by various researchers, who, on the one hand point out that the native-like use of discourse markers is "the hallmark of the proficient speaker" (Sankoff et al, 1997), while, on the other hand, even low-level language users are able to mimic the use of discourse markers in a target language, in effect feigning L2 competence. In some of the earliest work on codeswitching, Poplack (1981) noted, for example, English-sourced discourse markers you know and right by Spanish dominant speakers, which she took to reflect the 
fact that English was the matrix language in the community at large.

\author{
2.3 Pragmatic borrowing from a foreign language; problems with \\ terminology
}

As noted by Andersen (2014), the pragmatic borrowing research conducted so far often originates in communities where English has foreign language status. Such an outcome is hardly surprising, given the behavior of pragmatic elements such as discourse markers in contact situations in general. Likewise, in contact situations entailing unidirectional influence and diglossia, speakers tend to use discourse markers from the pragmatically dominant and/or "outside" language (Matras, 2009: 193). It is certainly clear that the influence of English is associated with the dominance and hegemony of Anglo-American culture; this topic has been thoroughly treated in the literature. It is also clear that, given its foreign language status, English is an "outside" language in locations such as Finland.

That said, the contact situation with English and Finnish is not easily characterized. The most comprehensive study on the role of English in Finland, based on questionnaire-based study with 1,495 responses, showed that, overall, English is viewed in Finland as something "other," yet an essential resource (Leppänen et al, 2009). Most respondents claimed that the role of English remains relatively distant and utilitarian, but for others, English figures intimately into their identity and everyday language use. Given the complexity $8 \mathrm{DR}$ 
of the situation, the applicable terminology in circulation remains underdescriptive in describing this type of language contact (see Laakso, 2013).

The literature on language contact has traditionally characterized such situations such as English in Finland as "weak" (see, e.g., Zenner, Speelman and Geeraerts, 2014) vs. "robust" or "rich." Such observations date back as far as Bloomfield (1933), who called the borrowing of linguistic elements from foreign languages "cultural borrowings" as opposed to "intimate borrowings," the latter referring to contact-related borrowings within a "topographically and politically" single community (Bloomfield, 1933: 461). In other words, "rich" or "intimate" language contact has been taken to mean that native speakers of Language $\mathrm{X}$ live in the same or adjacent geographical space with native speakers of Language Y. Indeed, the notion of geography and physical space figures into several contemporary descriptions of language contact; for example, Sayers (2014) discusses "non-contiguous" contact, referring to geographical territory. Meyerhoff (2006) constrasts "virtual" vs. a fixed locality, noting the "slippery space" in describing English contact in today's world (Meyerhoff, 2006: 245).

It is clear that the unidirectional influence of a dominant language and culture over others is not a new concept: what is new is the breadth and penetration of the influence of English, due in large part to the personal connection many language users have with English through new media forms. 
As noted by Androutsopoulos (2014), English becomes "highly untypical' [in comparison to previous influential languages] "with respect to a range of globally observable processes of contact-induced innovation and change, in which media plays a role" (Androutsopoulos, 2014: 245, emphasis original).

Despite such observations, many linguists appear reluctant to designate "global linguistic variants" (Buchstaller 2008, Sayers 2014) and to critically address the phenomenon. In 2014, the Journal of Sociolinguistics featured a discussion on the spread of linguistic variants via various forms of media, especially television. Various authors responded to a focus article which discussed possible media influence, using the quotative be like as the main example (Sayers, 2014). The responses to the article ranged from critical to cautiously supportive. Critical responses claimed that any possible media influence is most likely restricted to lexical borrowing and is, as such, not very interesting (Kristiansen, 2014; Trudgill, 2014). Other responses advanced that media influence is something that needs to be further investigated (Androutsopoulus, 2014).

In a setting like Finland, where more than 60 percent of the population claims to be fluent in English (see Leppänen, Nikula and Kääntä (eds.), 2008) and where English elements are commonplace in everyday spoken and written discourse, the question of whether or not the media plays a role in language contact between Finnish and English seems obvious to the point of banality. The ubiquitous presence of English-sourced linguistic elements in 
Finnish cannot be adequately explained by face-to-face or robust language contact-as addressed by Sayers (2014) with regard to "global variants," nor to parallel linguistic development (see Meyerhoff and Niedzelski, 2004; Trudgill, 2014), as Finnish is genealogically distant from English. Studies in Finland and the Nordic countries in recent years have demonstrated that increased involvement with media such as social networking sites and online gaming overlap with or even outpace the influence of the classroom when it comes to English (Piirainen-Marsh and Tainio, 2009; Sundqvist and Sylvén, 2014).

At the moment, there appears not to be a wholly satisfactory term for the type of language contact in question, which, in short, entails unidirectional influence from a dominant culture, entails varyingly intimate use among members of the recipient community, and is not a widespread native language within the recipient community. Terms describing the strength of the contact (e.g., weak, robust, strong) are ruled out because they do not account for the intricacies within the recipient community. Terms denoting physical space are ruled out because, as with English in Finland, the non-native language coexists in the same territory as the native language(s). Bloomfield's notion of cultural contact, defined previously, is applicable to some extent, yet in his original definition he noted that cultural contact is normally mutual (1933: 461), which is not the case here: Finnish does not influence English. Cultural contact is rendered further problematic due to contemporary adaptations; for example 
"cultural borrowing" is used to describe a new concept entering a language along with a term (see Myers-Scotton, 2002:41, who makes examples of hard drive, SUV and global warming). For now, due to lack of a better term, this article uses the term foreign language contact, harking to the official status of English in Finland.

\section{Contextualizing pragmatic borrowing}

This section attempts to demonstrate the social, pragmatic, and other incorporation processes of pragmatic borrowings, with the aim that these observations can be compared to similar phenomena in other languages. The linguistic examples presented in this article stem from Finnish, a language which has had a high level of interface with English as a foreign language since the period immediately following World War II, like many other European countries. Citing the work of Filipović from the 1960s and 1970s, Haugen (1988:2) observed that "[w]hat is surprising is that English words can in fact be found in every continental European language, from Albania to Iceland." Lexical borrowing goes hand-in-hand with domain-specific or "cultural borrowing," as defined earlier. It should be made clear, however, that with pragmatic borrowing, cultural gaps—and therefore domain-specific terminology—are not the primary object of investigation.

The focus in this article is on elements in Finnish discourse which are sourced from English, but which are used in a variety of settings and by a wide 
spectrum of people. However, it is relevant to point out that proficiency in English does not appear to be a prerequisite for incorporating pragmatic borrowings. As established in Section 2, the inherent properties of these pragmatic elements in borrowing situations make them both attractive and susceptible to use even among low- proficiency speakers of English.

In addition, as demonstrated in this section, pragmatic borrowings often have a semantic or grammatical equivalent in the recipient language. While this characteristic in and of itself is nothing new (see, e.g., Trudgill's lexical examples of wireless vs radio and clever vs smart, 2014: 215), the examples presented in this article demonstrate that the borrowed term and the heritage term seem to be in complementary distribution regarding pragmatic and social effect. At present, there is no evidence to advance that the borrowed form is replacing the native term or contributing to domain loss; at present it appears to simply offer a variable option.

\subsection{Social indices of pragmatic borrowings}

In recent years, it has been noted that the incorporation of English-sourced borrowings is often associated with youth language (see Andersen, 2014; Author, 2014; Sayers, 2014). Likewise, it has been observed that there exists a dichotomy regarding proficiency and use of English: on the one hand, it is associated with education and formal domains, for example in post-colonial settings, but, on the other hand, the use of English is associated with covert 
prestige and connection with global hip-hop and other youth movements-in

other words, a bottom-up/grassroots level of use (Pennycook, 2007;

Schneider, 2011).

The work on pliis 'please', in Finnish discourse shows similar findings involving language innovation in other settings; that is, the use of pliis is associated with young females, and especially with young, urban females (Author, 2014). The first documented example of pliis/please in Finnish discourse dates to 1944, in which a group of teenagers in the context of a film refer to "hot" American music, presumably meaning hot jazz. In the same conversational exchange, the teenagers employ the English politeness marker please (Paunonen and Paunonen 2000; see also Author, 2014). In this example, the combination of youth, cutting-edge music, rebellion, worldliness, and, at the same time, the use of (American) English serves as an early manifestation of the social indices still associated with English in Finland. In the intervening 60-plus years since this first attested use of pliis, the form has grown into a pragmatic borrowing in Finnish, whereas the term hot, a noun used in the same film to denote a certain type of music, has disappeared - presumably along with its referent (hot is used as an adjective in current Finnish discourse to mean 'current' or 'attractive').

A previous study comparing pliis to the native Finnish form kiitos (Author, 2014) was based on a grammatical acceptability and perceptual study involving 417 native speakers of Finnish. This study showed that not only is 
pliis associated with young, urban Helsinki females, but also that this is the social group which is more inclined to take "ownership" of the form. In response to the sample utterances containing the target form pliis, judgments ranged from dismissive ("pliis is so stabilized that even my grandmother uses it") to claims that its use was relegated to "whiny teenagers" and something that "not a man of any age" would say². The native form kiitos, on the other hand, did not carry the same social connotations as pliis, aside from the relevant point that both politeness markers pliis and kiitos are associated with women.

The results of this study, which reveal the language ideologies and perceptions about the forms pliis and kiitos, lend themselves well to an interpretation in the form of an indexical field. The sense of indexicality within the (variationist) sociolinguistic context espoused in this article is to be distinguished from that commonly used in research on discourse analysis or pragmatics. Rather than denoting, for example, deictic expressions, indexicality within the sociolinguistic community (connected to similar notions in linguistic anthropology, see Eckert 2008) has come to denote the continual reinterpretation of a given linguistic form in context, or how speakers position

\footnotetext{
${ }^{2}$ Quotations have been translated from the original Finnish: Mummonikin käyttää sanaa "pliis", niin vakiintunut se on ('"Pliis" is so stabilized that even my grandmother uses it'); Vähän valittava ja hyvin teinimäinen sanonta/kysmys ('A little bit whining and a very teenager-like expression/request'); Nuoren naisen lausuma, ei oikein minkään ikäisen miehen ('An expression of a young woman, not of a man of any age').
} 
themselves over time and in different constellations through a given linguistic form. An indexical field (Eckert, 2008: 469), then, is a means of visually representing the meanings speakers link to a linguistic form or a set of related forms. Figure 1 attempts to portray an indexical field showing speaker ideologies about pliis and kiitos, based on attitude research on these forms (Author, 2014).

\section{FIGURE 1 HERE}

Fig 1. Indexical field for pliis compared to kiitos, borrowed vs. native politeness markers in Finnish. Black (small caps) $=$ categories for pliis, gray $=$ categories for kiitos, boxes $=$ categories for both pliis and kiitos (modeled from Eckert, 2008: 469)

A strength of indexical fields is that that they offer a means of portraying the multiple perceptions of a given form within a speech community, which is evident in Figure 1. The figure captures the notion that respondents (Author, 2014) held mixed views about pliis; it was considered widespread in use, by all ages and genders, yet at the same time it was associated with young (urban) females, low social distance, and impure Finnish. Kiitos, as the standard, native Finnish form, retained its status as "pure" Finnish, but, in contrast to pliis, was deemed to be formal and traditional. Both pliis and kiitos were seen as potentially irritating and, as mentioned previously, both were associated with $16 \mathrm{DR}$ 
women. These last findings point toward an overall reluctance among Finnish people to use lexical politeness markers (Yli-Vakkuri, 2005) and an association of women with politeness forms.

\subsection{Pragmatic functions of pragmatic borrowings}

In addition to the social indices that seem to typify pragmatic borrowings from English into Finnish, a range of pragmatic outcomes and also pragmatic motivations become apparent.

One of the main findings in the work on pliis 'please' in Finnish (Author, 2014) is that, in comparison with the inherited Finnish politeness marker kiitos, pliis appears to be doing complementary work as a lexical politeness marker that shows positive politeness. While Finnish has morphemes and other lexical forms that indicate positive politeness, there was not previously a lexical politeness marker, per se. Thus, while the inherited form kiitos continues to serve as the standard and, as such, a stable form and a marker of negative politeness (see Wheeler 1994 on the inherent instability of positive politeness forms), pliis is associated with settings where solidarity and positive politeness are either present or strived for $^{3}$. Similar findings have been noted in other languages where English please has been borrowed; for example, Terkourafi (2011) draws similar conclusions about the use of please vs

\footnotetext{
${ }^{3}$ Continued work on pliis 'please' in Finnish makes use of naturally-occuring and corpus data (AUTHORS, 2015) and confirms that the actual use of the borrowing is for the most part consistent with the findings of the perceptual study of AUTHOR, 2014.
} 
parakaló in Cypriot Greek. It is important to note that these pragmatic properties differ from those found with respect to please in native Englishspeaking settings; while the use of please is best described as widely variable in pragmatic and social meaning (see, e.g., Aijmer, 2015), it is generally associated with conventionally indirect requests, for example Can I have some more milk, please? (Sato, 2008; Wichmann, 2005), and therefore with negative politeness.

The example of pliis thus demonstrates the perceived relationship of positive politeness with pragmatic borrowings from English, which presumably stems from the English-speaking cultures with which the forms are associated. In effect, it is as if the use of a borrowing from English licenses a behavioral and linguistic norm that is not seen as native (or possibly even appropriate) in the recipient culture or language (cf. Matras 2009 on "licensing" by bilingual speakers). ${ }^{4}$

Inherent in the notion of licensing from English is the occurrence of semantic bleaching, which is well documented, for example, with regard to

${ }^{4}$ An anecdotal example serves to illustrate "licensing" through English. During a visit to Sweden in December 2014, I witnessed an exchange between two native speakers of Swedish in a shopping mall. During their farewell sequence, the acquaintances hugged and said "Love you" in English as the final turn. It seems clear that saying Jag älskar dig 'I love you' in the same setting would have been embarrassing and potentially confusing to both the participants and their respective spouses, who were also present during the exchange (see Fiedler, this issue). Another anecdotal example comes from a colleague whose daughter, when pressed to apologize for naughty behavior, is willing to say the English borrowing sori'somy' but not the more facethreatening heritage Finnish form anteeksi (personal communication, 5 February 2015). 
English curse words in the discourse of recipient languages (see for example, Beers Fägersten, 2014, for Swedish and Dewaele, 2010, for other languages). A similar observation is made by Andersen (2014) and his treatment of the word fuck in Norwegian discourse. He makes an example of a Norwegian politician who wrote "Fuck Oslo" on her Twitter profile; this expression was later repeated in oral discourse by the leader of Norway's opposition party Venstre during a keynote address to the party convention. Andersen (2004:28) notes that it is highly improbable that either politician would have deemed it appropriate to write or say in Norwegian faen to Oslo 'fuck Oslo,' in either context.

In sum, I advance that the motivations for using pragmatic borrowings from English seem to involve (at least) three interrelated concepts: 1) the licensing of linguistic and social behavior that would not be appropriate or socially acceptable in the native language, 2 ) demonstration of positive politeness involving the source language cultural norms, and 3) semantic bleaching.

\subsection{Grammatical and semantic adaptation}

This section concludes with illustrations of how pragmatic borrowings from English are incorporated into Finnish both grammatically and semantically. The first example is the phrase oh my god; the second is the form about.

\subsection{1 oh my god}


In a study based on a network of 14-year-old girls from Helsinki, Antturi (2014) noted surprisingly few tokens of oh my god. This outcome not only countered her hypothesis that the use of oh my god would occur frequently, but also claims from the girls themselves, who reported high use of the form. This mismatch in perceived use vs. actual use was explained in part by the salience of the English-sourced form; similar observations about the prevalence of Anglicisms has been noted by other scholars, as well. For example, Sharp (2007) reports that Anglicisms account for only a small percentage of the overall word count of her spoken Swedish corpora, but she attributes the high estimation of English-sourced forms to their social salience. In the study of oh my god in Finnish (Antturi, 2014), a non-elicited, naturally-occuring 90-minute conversation between the four teenage girls yielded only four instances of oh my god. The same girls were instructed to note their usage of oh my god in everyday conversation, which resulted in an additional 10 tokens.

Like pliis, oh my god has functional equivalents in Finnish, such as herran jumala or minun luojani. However, the participants in the study (Antturi 2014) said the native term minun luojani was limited to use by older speakers, and that it was too pragmatically strong for everyday use. Thus, like oh my god in native English discourse, the phrase appears to be semantically bleached in Finnish, at least for the participants in this study.

Perhaps the most interesting finding about the use of oh my god is that the study participants claimed they were more likely to use the single-syllable $20 D R$ 
acronym [omg] than the three-syllable initialism [ov'zmger] (with the final syllable of the initialism reflecting the Finnish name for the letter "g"). To my knowledge, no studies have been conducted about the use of oh my god among speakers of English in native settings, but it would appear that the use of the initialism is more common than the acronym; the acronym points toward the phase being borrowed as a unit into Finnish, detached from its association with the full oh my god, as well as being derived from written language. ${ }^{5}$

The following example (1), taken from Antturi (2014:22), demonstrates how the two forms can be used within the same utterance:

(1) Oh my god must tuntuu et joku tulee tonne huoneeseen ja sit se on silleen omg te tapoitte hänet.

'Oh my god, I feel like someone is going to walk into that room and he'll be like, omg, you killed her.'

In this example from Antturi's (2014) audio-recorded data, the speaker first uses the variant oh my god, later followed by the acronym form omg.

\subsection{2 about}

In contemporary Finnish discourse, about appears to be used primarily as an

5It is noteworthy that the consonant sequence in [omg], that is, the bilabial nasal + velar stop, is phonotactically marked both in English and in Finnish (thanks to Peter Trudgill for this observation). 
adverb (Nykopp 2017)6. The form overlaps semantically and grammatically

with the native Finnish form noin 'about,' although it also demonstrates distinct properties. In fact, using a data set from the Finnish internet forum Suomi24, Nykopp (2013) found that Finnish about behaves in ways that distinguish it from both English about and Finnish noin, as shown in the following examples (2) and (3): ${ }^{7}$

(2) tyylini on about smart casual my style is about smart casual

(3) rasvaa ei tosiaan ollut about yhtään masussa there really was about no fat on my belly In (2) about has the meaning of 'something like.' In (3), the meaning of about is probably closest to 'virtually' or 'nearly' (Nykopp, 2013:19). In both cases, it is safe to state that about would not be idiomatic in such an utterance in English, nor could the Finnish form noin be used. In other words, such examples indicate a distinct, non-English pattern of use for the borrowing about in Finnish.

Further, like the comparison of the Finnish politeness markers pliis and

\footnotetext{
${ }^{6}$ Currently, the investigation of about in Finnish discourse continues (personal communication with Liisa Nykopp, April 2016). In Nykopp (expected 2017), examples of about as an adverb in Finnish discourse: 1) haluaisin että se kulkisi $60 \mathrm{~km} / \mathrm{h}$ about 'I would want it to go about $60 \mathrm{~km} / \mathrm{h}$ ' 2) [se] roikku Saran otsalla about kulhoon asti. '[it] hung on Sara's forehead almost to the bowl.' ${ }^{7}$ In addition to spelling, the form about has distinct pronunciation in Finnish. Because the study by Nykopp (2013) made use of written data, spoken adaptation is not considered.
} 
kiitos, the pair about and noin also demonstrate a similar indexical field in terms of pragmatic and social effect (again, based on Nykopp 2013). About, while showing distinct grammatical properties that make it clearly a borrowing into Finnish, at the same time retains its associations with English, youth, urbanicity, informality, and low social distance.

\subsection{Adoption and adaptation of pragmatic borrowings}

An important point emerges from the examples presented in this section: once a form gains a foothold in the recipient language as a borrowing, there is a distinct probability that it ceases to function like the donor form from the source language. For example, it is not certain that a native speaker of English in places like the United States or the United Kingdom would say [omg] rather than [ov'3:mdzi:]. Likewise, the examples in this section demonstrate that the borrowings from English into Finnish are pragmatically, semantically and grammatically distinct from the source forms in English. As such, it can be argued that, rather than conducting comparative studies of the functional range of these forms in the source language and recipient language, as suggested by Andersen (2014), the more fruitful and revealing investigation lies in a comparison of the pragmatic borrowing and its functions with the form(s) already in the recipient language.

Further, while Andersen's (2014) term pragmatic borrowing in its original form was defined as applying to interjections, discourse markers, 
expletives, vocatives, general extenders, and other linguistic forms that could be said to fit within the rubric of pragmatic elements of language, the term aptly applies to a wider set of linguistic forms as well, as demonstrated here (for example, about). In further studies of this contact phenomenon, it would be beneficial to expand the definition of pragmatic borrowing to describe the motivation for borrowing, rather than the types of forms that are borrowed. That is, pragmatic borrowing would refer not specifically to the borrowing of pragmatic linguistic elements such as discourse markers, but rather to the pragmatic reasons for borrowing -including the cultural and social motivations discussed in this article. In shifting the definition of pragmatic in pragmatic borrowing to a process rather than an outcome, the term applies to a much wider range of linguistic phenomena that seem part of a similar social and pragmatic process (for similar discussions, see the articles by Andersen, Andersen et al. and Mišić Ilić in this issue).

A final point to be made is that, while the contextualization features discussed in this section have been divided into classes such as pragmatic, social, and grammatical, there is no indication that these forces are mutually exclusive. On the contrary, there is ample reason to assume that these characteristics cluster around a given form in an overlapping manner. Further, there are no doubt many other explanations about the incorporation of pragmatic borrowings in other settings and in other languages that are yet to be confirmed. 


\section{From code-switching to borrowing - or not}

As discussed previously, it has been established that the elements now referred to as pragmatic borrowings enter into a specific language or discursive situation as a communicative resource by a speaker (bilingual or not) who inserts the borrowed element into native discourse for social, pragmatic and performative motivations. As in other borrowing situations, if a form is subsequently picked up and used by the same speaker and others, it has the potential to gain a foothold in the receiving community. In turn, it may be further shaped and adapted by the community, a process which, of course, is known as nativization, adaptation, or integration.

An example of this process can be made of the form pliis, which, as discussed previously, was first attested in a Finnish film dating from 1944. In this instance, the (presumably) insertional borrowing please was used to index a range of associations that include youth, urbanicity, connection to a world outside of Finland, and global culture (in this case, America and jazz music). In the second stage of development, the form in question takes on an established use within a certain community, likely a young, urban group of speakers, as depicted in the film Suomisen Olli rakastuu 'Olli Suominen falls in love,' or as in the perceptual study of pliis in Finnish (Author, 2014). While continuing to index the same social and pragmatic values which prompted its use in the first place, the form continues to become embedded into Finnish discourse, taking on a 
Finnish spelling, pronunciation, morphology, as well as pragmatic, semantic and social properties which are distinctly Finnish. This trajectory is summarized in Figure 2.

[[Figure 2 here]]

By means of arrows, Figure 2 attempts to account for the passage of time with relation to a form, as well as to the process of integration itself. The figure also attempts to portray, through the use of dotted lines, that part of the motivation for borrowing an element includes the indices the form carries with it; even over time, these indices remain intact, although the form undergoes various adaptation processes.

It becomes clear that English pragmatic borrowings enter into Finnish discourse as social and pragmatic decisions; these linguistic forms are above the level of consciousness, not examples of mechanical diffusion (Kristiansen, 2014). Also captured in the figure is the notion that the process can and does stop at any point of the process, due to intervening factors or simply because a form does not gain a foothold. An example can be made of the form hottia, presumably 'hot jazz,' which was present in the same utterance as please in the film Suomisen Olli rakastuu. While pliis, an example of a pragmatic borrowing, has gone on to become commonplace in Finnish discourse, the term hottia, best described as a cultural borrowing (i.e., 
filling a lexical gap in the recipient language) has died out with the style of music it denoted.

The motivations for experimenting with a borrowing from English in the first place - that is, to index perceived urban, youth, and global orientations - can be viewed quite positively, depending on the speaker and audience. At the same time, however, there is an inherent risk involved with using an English borrowing if the speaker, the setting, and the audience provide a mismatch in values. In such a situation, experimentation with an English-sourced borrowing will not pass stage one of the trajectory, or in other words it will not be carried past the point of codeswitching or idiolectal use.

An example of such a failure comes from the idiolect of the public figure Matti Nykänen, a former Finnish ski jumping champion who is now an established tragic hero. For decades, Nykänen's private life has been fodder for tabloid journalism. Part of his appeal in the media is his colorful use of language, which features numerous English-sourced elements. It appears, however, that he does not serve as a language trendsetter, as his language use is not picked up and used by the larger Finnish-speaking community in everyday discourse; this despite the fact that many of his expressions have been known for decades. For example, one of his most famous phrases, "Elämää on laiffii”' 'Life is about (life)' makes use of the English-sourced laiffii 'life' to denote a version of life that is big, bold and hard-fought. However, 
this use of laiffii does not seem to exist aside from Nykänen. ${ }^{8}$ Unlike pragmatic borrowings which have made it past stage 1 of the trajectory, laiffii has not become a variant of the heritage Finnish elämä 'life'; rather, the nonadoption of this form points toward a disassociation with a speaker (or type of speaker), reminiscent of what has been called a "distancing process" (Eckert, 2008:462).

The use of a pragmatic borrowing from English presents a risk even if a form is established in mainstream Finnish. Instances of such rejection are seen as confirmation that English-sourced borrowings retain a non-native flavor and therefore a potentially distancing property. An example of the risk involved comes from the use of the borrowing c'mon, also written as c'moon and kamoon (among other variants) in Finnish. In 2013, the Finnish chef Hans Välimäki ${ }^{9}$ defended his choice to charge customers in his restaurant for regular tap water - a practice that was previously unheard of in Finland. The resulting dispute, dubbed "Watergate" and subsequently reported by local media, featured the use of c'moon in written discourse from Välimäki, on his restaurant's public Facebook site:

(4) Niin ja henkilökunta on ilmaista, joka ne lasit sinne kiikuttaa? C'moon. Ainahan voi valittaa ja saakin, mutta pitää olla perusteita. Kotona on ilmaista. Ei ravintoloissa.

\footnotetext{
${ }^{8}$ A Google search of the phrase Elämää on laiffii shows 33,000 hits, all of which appear to be linked explicitly or indirectly to Nykänen himself.

${ }^{9}$ Thanks to Jani Ahtiainen, an attendee at the first Changing English conference in 2013, hosted by the University of Helsinki, for sharing this example. 28DR
} 
'Yeah, and the staff that brings you the glass costs nothing? C'moon.

You can and may complain, but you have to have a reason. At home it's free. Not in a restaurant.'

(http://www.city.fi/opas/hans+valimaen+midhill+ajoi+some\%C2\%ADmiinaan/7331)

The inclusion of the English-sourced c'moon in the utterance appears to be a strategy in accordance with the properties described in Section 3.2; or in other words an appeal to positive politeness, keeping an informal tone, and in an attempt to gain solidarity. The other language use in the utterance supports such an interpretation.

Hundreds of written responses demonstrated anger over the propositional content of the utterance in (4), but several specifically latched onto the use of c'moon, clearly making fun of it by mimicking the original spelling and using it in utterances where it is not idiomatic:

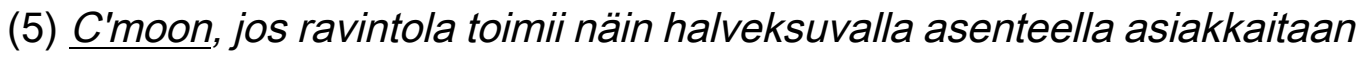
kohtaan, niin vien rahani toisaalle.

'C'moon, if a restaurant treats it customers with such spite, I'm taking my money elsewhere.'

(6) C'moooon, paljonko maksaa jos haluais kans käyttää veistä ja haarukkaa?

C'moooon, how much do I have to pay if I want to use a knife and fork? The utterances in (5) and (6) demonstrate the use of c'moon was not positively 
interpreted by all potential audience members, and, in fact, that it offered an opportunity for ridicule. This examples serves to illustrate that the use of English-sourced borrowings, even established ones, can be potentially divisive if used with a non-sympathetic interlocutor.

5. Conclusions: foreign language contact and pragmatic borrowing

The language contact phenomenon described in this article as pragmatic borrowing refers to the adaptation of a class of lexical items and phrases that are non-specialized, non-domain specific features which include (but are not limited to) interjections, idioms, particles, discourse markers and politeness markers. It is argued that this collection of features is prone to borrowing in language contact settings in general, but perhaps especially in foreign language contact settings. Traditionally, the entrance of a foreign-sourced lexical item has been associated with bilingual speakers, but it is argued here that this is not a prerequisite for pragmatic borrowings.

A central claim in the article is that the motivation for such borrowings is pragmatic in nature-and hence a proposed shift the term pragmatic borrowing from referring strictly to pragmatic elements (as per Andersen 2014), to pointing to an element which enters a recipient language due to pragmatic and social motivations. A second claim is that a pragmatic borrowing seems to work in a complementary fashion with a heritage equivalent, creating what is perceived by native speakers as a variant that co30DR 
habitates with a pre-existing form; in other words, the pragmatic borrowing does not replace the stable, often standard, heritage form. Rather, the borrowed form carries indexicalities such as youth and urbanicity. Such borrowings are argued to be alternatives to the heritages forms in regard to pragmatic functions such as positive politeness, semantic bleaching, and licensing.

A third main point is that pragmatic borrowings from English are incorporated into Finnish in such a way that distinguishes them from both the English source as well as the pre-existing heritage equivalent. The forms acquire social, pragmatic, and even grammatical values that appear to be unique to their purpose in Finnish.

A related point addresses foreign language contact and the role of a widespread lingua franca or foreign language such as English. This exact type of language contact, from a modern (global) perspective, is not widely discussed in the literature on language contact. It seems that the notion of pragmatic borrowing, and further investigation of this phenomenon in other languages, would help answer questions that right now remain unanswered such as what effect, if any, does English (or other widespread lingua francas) have on the grammatical and pragmatic system of recipient languages? A further concern is how to best term this type of contact.

\section{References}

Aijmer, Karin, 2015."Will you fuck off please." The use of please by London teenagers. Jódete por favor". El uso de please por parte de los adolescents londinenses. Pragmatica Sociocultural/Sociocultural Pragmatics 3 ( 2 ), 127-149 
Andersen, Gisle, 2014. Pragmatic borrowing. Journal of Pragmatics 67, 17-33.

Androutsopoulos, Jannis, 2014. Beyond "Media Influence." Journal of Sociolinguistics, 18(2), 242-249.

Antturi, Sofia, 2014. "Oh my god oh my god oh my god! mä en saa henkee!" English interjection in Finnish discourse. Unpublished BA thesis, University of Helsinki, Department of Modern Languages.

Beers Fägersten, Kristy, 2014. The use of English swear words in Swedish media. In Marianne Rathje, Swearing in the Nordic Countries (pp. 63-82). Copenhagen: Dansk Sprognævn.

Bloomfield, Leonard, 1933. Language. New York City, New York, USA: Holt.

Buchstaller, Isabelle, 2008. The localization of global linguistic variants. English World-Wide 29: 15-44.

Dewaele, Jean-Marc, 2010. Emotions in Multiple Languages. New York, NY, USA: Palgrave Macmillan.

Eckert, Penelope, 2008. Variation and the indexical field. Journal of Sociolinguistics 12 (4), 453-476.

Haugen, Einar, 1988. The influence of English: a transatlantic perspective. Folia Linguistica 2 (1-2), 3-10.

Kristiansen, Tore, 2014. Knowing the driving force in language change: Density of subjectivity. Journal of Sociolinguistics 18 (2), 233-241.

Laakso, Johanna, 2014. Contact and the Finno-Ugric Languages. In Raymond Hickey (Ed.), The Handbook of Language Contact. Malden, MA: Wiley-Blackwell, 598-617.

Leppänen, Sirpa, Tarja Nikula and Leila Kääntä (Eds.), 2008. Kolmas kotimainen: Lähikuvia englannin käytöstä Suomessa [The Third Domestic Language: Case Studies on the Use of English in Finland]. Helsinki: Suomalaisen kirjallisuuden seura.

Leppänen, Sirpa, Anne Pitkänen-Huhta, Tarja Nikula, Samu Kytölä, Timo Törmäkangas, Kari Nissinen, Leila Kääntä, Tiina Virkkula, Mikko Laitinen, Päivi Pahta, Heidi Koskela, Salla Lähdesmäki \& Henna Jousmäki. 2009a. Kansallinen kyselytutkimus englannin kielestä Suomessa: Käyttö, merkitys ja asenteet [National Survey on the English Language in Finland: Uses, Meanings and Attitudes]. Jyväskylä Studies in Humanities 132. http://urn.fi/URN:ISBN:978-951-39-3815-4.

Maschler, Yael and Deborah Schiffrin, 2015. Discourse markers: Language, meaning, and context. In Deborah Tannen and Heidi Hamilton (Eds.), The Handbook of Discourse Analysis (second ed.), 189-221. Oxford, United Kingdom: Blackwell.

Matras, Yaron, 2009. Language Contact. Cambridge, UK: Cambridge. Meyerhoff, Miriam, 2006. Introducing Sociolinguistics. Routledge. Meyerhoff, Miriam and Nancy Niedzelski, 2003. The Globalisation of Vernacular Variation. Journal of Sociolinguistics 7 (4): 534-555. Mougeon, Raymond and Edouard Beniak, 1991. Linguistic consequences of 32DR 
language contact and restriction. Oxford, United Kingdom: Oxford University Press.

Muysken, Pieter, 2013. Scenarios for Language Contact. Raymond Hickey

(Ed.), The Handbook of Language Contact. Malden, MA: WileyBlackwell, 265-281.

Myers-Scotton, Carol, 2002. Contact Linguistics: Bilingual Encounters and Grammatical Outcomes. Oxford, United Kingdom: Oxford University Press.

Müller, Simone, 2005. Discourse Markers in Native and Non-native English Discourse. Amsterdam: John Benjamins Publishing Company.

Nortier, Jacomine and Margreet Dorleijn, 2013. Multi-ethnolects: Kebabnorsk, Perkerdansk, Verlan, Kanakensprache, Straattaal, etc. In Peter Bakker and Yaron Matras (Eds.) Contact Languages: A Comprehensive Guide. Berlin: de Gruyter.

Nykopp, Liisa, 2013. "Sanamuoto about näin": The Use of About in Finnish Discourse. Unpublished BA thesis, University of Helsinki: Department of Modern Languages.

Nykopp, Liisa, 2017. The Anglicism About in Informal Written Finnish Discourse. MA thesis, University of Helsinki: Department of Modern Languages. Available at https://helka.finna.fi/Record/metalib_hy.FIN30485

Paunonen, Heikki and Marjatta Paunonen, 2000. Tsennaaks Stadii, bonjaaks slangii: Stadin slangin suursanakirja [The dictionary of Helsinki slang]. Helsinki, Finland: WSOY.

Pennycook, Alistair, 2007. Global Englishes and Transcultural Flows. London, UK: Routledge.

Pennycook, Alistair and Emi Otsuji, 2015. Metrolingualism: Language in the city. London and New York: Routledge.

AUTHOR

AUTHOR

Piirainen-Marsh, Arja and Liisa Tainio, 2009. Other-repetition as a resource for participation in the activity of playing a video game. The Modern Language Journal 93 (2), 153-169.

Poplack, Shana. 1981. Syntactic structure and social function of code-switching. In Latino Language and Communicative Behavior, ed. by Duran, R., 169184. New Jersey: Ablex Publishing Corp.

Quist, Pia, 2008. Sociolinguistic approaches to multiethnolect: Language variety and stylistic practice. International Journal of Bilingualism 12 (1 \& 2), 43-61.

Saarikivi, Orvo (director). (1944). Suomisen Olli rakastuu 'Olli Suominen Falls in Love.' Suomen Filmiteollisuus.

Sankoff, Gillian, 2001. Linguistic Outcomes of Language Contact. In P. Trudgill, J. Chambers, and N. Schilling-Estes (Eds.), Handbook of Sociolinguistics (pp. 638-688). Oxford, UK: Basil Blackwell. 
Sankoff, Gillian, Pierette Thibault, Naomi Nagy, Helene Blondeau, Marrie-Odile Fonollosa \& Lucie Gagnon. 1997. Variation in the use of discourse markers in a language contact situation. Language Variation and Change 9, 191-217.

Sato, Shie, 2008. Use of "please" in American and New Zealand English. Journal of Pragmatics 40. 1249-1278.

Sayers, Dave, 2014. The mediated innovation model: A framework for researching media influence in language change. Journal of Sociolinguistics 18 (2), 185-212.

Schiffrin, Deborah, 1987. Discourse Markers. Cambridge: Cambridge University Press.

Schneider, Edgar, 2011. English around the World. Cambridge: Cambridge University Press.

Sharp, Harriet, 2007. Swedish-English language mixing. World Englishes 26 (2), 224-240.

Sundqvist, Pia and Liss Kerstin Sylvén, 2014. Language-related computer use: Focus on young L2 English learners in Sweden. ReCALL 26 (1), 3-20. doi: 10.1017/S0958344013000232

Terkourafi, Marina, 2011. Thank you, Sorry, and Please in Cypriot Greek: What happens to politeness markers when they are borrowed across languages? Journal of Pragmatics 43, 218-235.

Thomason, Sarah G. and Terrence Kaufman, 1988. Language contact, creolization, and genetic linguistics. Berkeley, Los Angeles, London: University of California Press.

Thomason, Sarah G., 2001. Language Contact. Edinburgh: University of Edinburgh Press.

Trudgill, Peter, 2014. Diffusion, drift, and the irrelevance of media influence. Journal of Sociolinguistics 18 (2): 214-222.

Wheeler, Max, 1994. Folia linguistica historica 15 (1/2), 149-174.

Wichmann, Anne, 2005. Please: from courtesy to appeal: the role of intonation in the expression of attitudinal meaning. English Language and Linguistics 9 (2), 229-253.

Winford, Donald. 2001. An Introduction to Contact Linguistics. Wiley-Blackwell. Yli-Vakkuri, Valma, 2005. Politeness in Finland: Evasion at all costs. In L. Hickey and M. Stewart (Eds.), Politeness in Europe, 189-202. Clevedon, UK: Multilingual Matters.

Zenner, Eline, Dirk Speelman and Dirk Geeraerts, 2014, February 27. A sociolinguistic analysis of borrowing in weak contact situations: English loanwords and phrases in expressive utterances in a Dutch reality TV show. International Journal of Bilingualism, 1-14. 